\title{
вMJ Global Health Weak surveillance and policy attention to cancer in global health: the example of Mozambique
}

\author{
Cesaltina Lorenzoni, ${ }^{1,2}$ Laura Oliveras, ${ }^{3,4}$ Alba Vilajeliu, ${ }^{3,4}$ Carla Carrilho, ${ }^{1,2}$ \\ Mamudo R Ismail, ${ }^{1,2}$ Paola Castillo, ${ }^{3,5}$ Orvalho Augusto, ${ }^{6}$ Mohsin Sidat, ${ }^{6}$ \\ Clara Menéndez,, ${ }^{3,7}$ Alberto L Garcia-Basteiro, ${ }^{3,7,8}$ Jaume Ordi $^{3,5}$
}

To cite: Lorenzoni $\mathrm{C}$, Oliveras L, Vilajeliu A, et al. Weak surveillance and policy attention to cancer in global health: the example of Mozambique. BMJ Glob Health 2018;3:e000654. doi:10.1136/ bmjgh-2017-000654

Handling editor Seye Abimbola

$\mathrm{CL}, \mathrm{LO}$ and $\mathrm{AV}$ contributed equally.

$\mathrm{CL}, \mathrm{LO}$ and $\mathrm{AV}$ are shared first authors.

Received 21 November 2017 Revised 20 February 2018 Accepted 24 February 2018

Check for updates

For numbered affiliations see end of article.

Correspondence to Dr Alberto L Garcia-Basteiro; alberto.garcia-basteiro@ manhica.net

\section{ABSTRACT}

Cancer is an emerging public health problem in subSaharan Africa due to population growth, ageing and westernisation of lifestyles. The increasing burden of cancer calls for urgent policy attention to develop cancer prevention and control programmes. Cancer surveillance is an essential prerequisite. Only one in five low-income and middle-income countries have the necessary data to drive policy and reduce the cancer burden. In this piece, we use data from Mozambique over a 50-year period to illustrate cancer epidemiological trends in low-income and middleincome countries to hypothesise potential circumstances and factors that could explain changes in cancer burden and to discuss surveillance weaknesses and potential improvements. Like many low-income and middle-income countries, Mozambique faces the dual challenge of a still high morbidity and mortality due to infectious diseases in rural areas and increased incidence of cancers associated with westernisation of lifestyles in urban areas, as well as a rise of cancers related to the HIV epidemic. An increase in cancer burden and changes in the cancer profile should be expected in coming years. The Mozambican healthcare and health-information systems, like in many other lowincome and middle-income countries, are not prepared to face this epidemiological transition, which deserves increasing policy attention.

\section{INTRODUCTION}

Cancer is an emerging public health problem in sub-Saharan Africa. ${ }^{1}$ According to GLOBOCAN 2012 estimates, there were 626399 new cancer cases in sub-Saharan Africa in 2012, which represents $4.4 \%$ of the 14.1 million worldwide new cancer cases and almost the same number of estimated cancer cases in 2008 for the whole African Region (667 000 incident cases). Regarding mortality, $5.5 \%$ of the 8.2 million estimated deaths in 2012 occurred in sub-Saharan Africa (447 745 deaths), again close to the 518000 deaths estimated in 2008 for the whole African Region. ${ }^{23}$ This increase is partly related to population growth and ageing, but also to westernisation of lifestyles. ${ }^{14}$ Although 25\%

\section{Key questions}

What is already known about this topic?

- Cancer is an emerging public health problem in low-income and middle-income countries due to population growth, ageing and westernisation of lifestyles.

\section{What are the new findings?}

- The increasing cancer burden will have major implications for public health and clinical services planning and a great impact in low-income and middle-income countries without strong health systems.

- Healthcare and health-information systems in countries like Mozambique might not be prepared to face this epidemiological transition.

\section{Recommendations for policy}

- Cancer deserves increasing policy attention. Countries like Mozambique should work simultaneously in population awareness, the establishment of a national cancer registry and demographic information with higher quality and coverage and the strengthening of health systems to implement cancer prevention and control programmes.

- Development of networks and coordination with organisations providing support and sharing knowledge such as the Global Initiative for Cancer Registry Development should be prioritised.

of all cancers in low-income and middle-income countries (LMIC) are still estimated to be infection related, ${ }^{2}$ societal and economic development is linked to behavioural and lifestyle changes, associated with conventional industrialised countries cancer risk factors. For this reason, an epidemiological transition is expected in many low-resourced settings, with profound effects on the magnitude and profile of the cancer burden. ${ }^{4}$ Unquestionably, this will have major implications for public health and clinical services planning 
and a great impact in LMIC without strong health systems, which at the same time, are also expected to experience the greatest proportional population growth in the next years and, thus, the greatest increase in cancer burden.

Cancer surveillance with robust statistics on cancer incidence, morbidity, survival and mortality, is an essential prerequisite for national and regional cancer control programmes. It is also essential for targeted operational research outputs. However, there is a lack of vital statistics and population-based registries in LMIC. ${ }^{4}$ An encouraging step forward is The Global Initiative for Cancer Registry Development (GICR), a coordinated, multipartner approach that aims to reduce the incidence, mortality and suffering due to cancer in the world's poorest regions through high-quality data that inform cancer control. According to GICR, only one in five LMICs have the necessary data to drive policy and reduce the burden and suffering due to cancer. ${ }^{5}$

A global view of cancer patterns and trends in relation to national level of development becomes an imperative to understand changes in the cancer burden and its major causes and to raise policy attention to develop control and prevention strategies. The aim of this piece is to illustrate these challenges using the example of cancer epidemiological trends in a low-income country, to hypothesise potential circumstances and factors that could explain the cancer burden changes and to discuss surveillance weaknesses and potential improvements. For that, we use the case of Mozambique, one of the poorest countries in sub-Saharan Africa, but with fast social and economic development.

We analysed socioeconomic changes, cancer epidemiological trends, weaknesses and potential strengths for cancer surveillance over a 50-year period. Epidemiological data were mainly obtained from two big cancer surveys, which cover today's Maputo City area for the periods $1956-1961^{6}$ and $1991-2008,{ }^{7}$ respectively.

\section{THE EXAMPLE OF MOZAMBIQUE}

\section{Fifty years of important social and economic changes}

In 1956, Mozambique was still a Portuguese colony. Lourenço Marques (today Maputo city) was a commercial and administrative centre and a busy port with a population of about $100000 .{ }^{8}$ The city was undergoing the simultaneous process of urbanisation, detribalisation and assimilation of Western culture. Mozambique already had one of the least developed colonial economies when, in 1975, it gained independence. After independence, Mozambique quickly constructed a primary healthcare system based on principles defined at the transformative 1978 Alma-Ata conference, ${ }^{9}$ but 16 years of civil war destroyed infrastructures, ruined livelihoods and severely hampered agricultural production and economic development. ${ }^{10}$ The conflict and the subsequent natural disasters (severe floods and droughts) forced the internal and external displacement of many families. Since the first multiparty election of 1994, the economy has been recovering with some of the fastest growth rates in the world. ${ }^{11}$

Mozambique, a malaria endemic country, has also been hard hit by the HIV and tuberculosis dual epidemic, ${ }^{12}$ which compromises the country's social and economic progress. Since the 1990s, the HIV has shown an extremely rapid progression, affecting, in some settings, up to $45 \%$ in women aged 28-47 as reported in a recent community-based study in a rural district of Maputo province. ${ }^{13}$

Despite more than 20 years of relatively stable political context, Mozambique is still one of the world's poorest countries, with a Human Development Index of 0.461 (ranking at 180 out of 188 countries) and $44.1 \%$ of population in severe multidimensional poverty. ${ }^{14}$ Since the start of the first nationwide education and literacy campaign in 1975, the adult illiteracy rate has notably, but not sufficient, decreased from $97 \%$ to $56 \% .{ }^{6}{ }^{15}$ Life expectancy remains low, although from 1960 to 2008 raised from 35 to 52.2 years. ${ }^{16}$ Nowadays, the country is facing the consequences of urbanisation and westernisation of lifestyle, which coexist with an extremely high burden of traditional infectious diseases of poverty, a new political crisis, an important economic instability and a fragile and under-resourced health system. ${ }^{191117}$ Since the structural adjustment programme sponsored by the International Monetary Fund to pay back debt in 1987, Mozambique's health system has been struggling with the huge cuts to public spending and the constraint of foreign aid for strengthening the national health system. ${ }^{9}$

\section{Cancer patterns and trends in Mozambique}

Although cancer surveillance data in Mozambique is still far away from desired standards, the availability of two big cancer surveys in today's Maputo area for the periods 1956-1961 and 1991-2008 is uncommon compared with other LMIC. As summarised in table 1, there are significant methodological limitations that restrict the comparison and trend analysis of available data; even so, we believe that a cautious analysis can provide valuable information to address the cancer challenges in Mozambique.

Cancer incidence rates have varied considerably during the last decades in Maputo, as shown in table 2. We observe an increase from 169.9 cases per 100000 in 1956-1961 to 182.7 in 1991-2008 in men and from 95.3 to 186.0 cases per 100000 in women. Although the different age distributions standards used in both assessments can hinder precise comparisons between different populations considerably, there is no doubt that the cancer notification rates in Mozambique have generally experienced a remarkable increase. Whereas between 1956 and 1961, a total of 600 cancers (403 in men, 197 in women) were registered, between 2003 and 2008, 6743 cases of cancer were identified (2900 in men, 3818 in women and 25 people without gender information). ${ }^{67}$

This startling increase in absolute numbers of more than seven times in men and more than 19 times in women may be related to different processes. First of all, Maputo had a population of about 100000 in the early 
Table 1 Methodological differences between the two surveys that restrict the comparison and trend analysis of data

\section{Survey 1956-1961}

Survey 1991-2008

\begin{tabular}{ll}
\hline Covered area & Urban and periurban area of about $60 \mathrm{~km}^{2}$ at that time Today's Maputo city \\
Lourenço Marques (today's Maputo city).
\end{tabular}

Type of registry Population-based registry: it included every tumour diagnosed in Miguel Bombarda Hospital (MBH), the two missionary hospitals and the outpatient's clinics (private and state controlled) in Lourenço Marques. Data of new cancer cases were obtained of biopsies and autopsies performed by the department of pathology of the $\mathrm{MBH}$, but also of home visits.

Population estimates

Age estimates and standard populations for age-standardised rates
Due to the steady influx of African rural workers seeking employment in Lourenço Marques, the 1950 census was even more inadequate than African census records usually are. ${ }^{6}$ In 1957-1958, a sample survey was conducted to ascertain accurate demographic data. At that time, there were no house numbers or guiding maps, random sampling was done using aerial photographs and included the three main residential strata at that time: servants and labourers living on employers' premises in central area of the town, suburban dwellers living in their own houses on the immediate outskirts of the central area and periurban population. A total of 4291 men and women were included to calculate the population estimates of age and sex distribution.

Due to the high illiteracy rate at the time $(97 \%$ before the first literacy campaign in 1975), estimating patients' age was a big challenge. Surveyors were specially trained to establish the age by questioning about critical periods or historical events. Age-standardised rates were calculated using the Standard African Population, a less westernised standard adequate for comparison with other territories of Africa.
Laboratory-based registry: it included all tumours diagnosed by anatomopathological test performed in the department of pathology of the Maputo Central Hospital. The department also receives samples of other public and almost all private health units in the city.

The first postcivil war Mozambican census was performed in 1980. Although their precision can be questioned, data of the 1980, 1987 and 2007 census were available and intercensual estimates could be calculated.
The World Standard Population proposed by Segi (1960) was used for age standardisation. This standard is widely adopted, but it reflects to a greater extent population with relatively low fertility and mortality giving more weight to the middle years of life. Applying this standard to 'younger' populations can misstate the true level of estimates. ${ }^{38}$

Extrapolation of data In both cases, surveys were restricted to today's Maputo city area. Information of other sites of the country and especially of rural areas is needed for a national-wide extrapolation.

$1960 \mathrm{~s},{ }^{8}$ which increased markedly until the 2007 census where it reached 1094628 inhabitants. In addition, cancer is an affliction that normally occurs later in life. From 1960 to 2008, the life expectancy in Mozambique raised from 35.0 to 52.2 years. Furthermore, improvements in education and healthcare access and the introduction of new diagnostic techniques may have played a role in increased cancer detection. Prates and Torres ${ }^{6}$ mentioned that men used healthcare services for general treatment more frequently than women did, although most women stated that if sick they would seek treatment at a clinic or hospital. The authors suggested that the reduced access to healthcare in women could be related to the fact that by that time, before making a decision, women must obtain permission from the head of the family who could have been absent as a migrant labourer. Increased women's access to maternal and reproductive health services, evidenced by the gradual reduction in maternal mortality, could also explain the increased notification rates in women observed by Lorenzoni and colleagues. ${ }^{7}$

Regarding to the specific cancer burden profile, today Mozambique presents, as many other LMIC, a dual burden with a still high incidence of cancers associated with infectious diseases and an increasing incidence of cancers related to lifestyle risk factors. In the last decades, the country has experienced important downward trends in infection-related cancers such as primary carcinoma of the liver or cancer of the urinary bladder, but unfortunately, HIV-related cancers have experienced a substantial increase. As expected due to the westernisation of lifestyles, some of the most common cancers in high-income countries, such as prostate or breast cancer, have experienced enormous increase in Mozambique. Such trend has not been observed in lung cancer incidence, which remains still low. Prates and Torres (1956-1961) recorded the highest incidence of primary carcinoma of the liver for any part of the world, with age-standarised 
Table 2 Age-standardised incidence rates (per 100 000) in the periods from 1956 to 1961 and 2003-2008.

\begin{tabular}{|c|c|c|c|c|}
\hline & \multicolumn{2}{|l|}{ Males } & \multicolumn{2}{|l|}{ Females } \\
\hline & \multicolumn{2}{|c|}{ Age-standardised rate per 100000} & \multicolumn{2}{|c|}{ Age-standardised rate per 100000} \\
\hline & $1956-1961^{*}$ & $2003-2008 \dagger$ & $1956-1961^{*}$ & 2003-2008† \\
\hline Total, all sites & 169.9 & 182.7 & 95.3 & 186.0 \\
\hline Oral cavity, pharynx & 3.8 & 5.0 & 4.8 & 4.5 \\
\hline Oesophagus & 3.2 & 8.7 & - & 9.9 \\
\hline Stomach & 1.0 & 1.6 & 0.6 & 1.0 \\
\hline Colon-rectum & 2.0 & 6.3 & 0.7 & 2.7 \\
\hline Liver & 109.7 & 14.1 & 28.8 & 8.3 \\
\hline Pancreas & 0.9 & 0.4 & 0.7 & 0.3 \\
\hline Trachea, bronchus, lung & 3.2 & 2.6 & 2.5 & 1.7 \\
\hline Other connective and soft tissue & 3.8 & 4.4 & 1.7 & 3.1 \\
\hline Breast & - & - & 2.4 & 26.2 \\
\hline Uterine cervix & - & - & 20.3 & 62.0 \\
\hline $\begin{array}{l}\text { Other tumours of the female genital } \\
\text { tract }\end{array}$ & - & - & 4.0 & 10.8 \\
\hline Prostate & 3.4 & 61.7 & - & - \\
\hline Penis & 2.1 & 3.6 & - & - \\
\hline Kidney & 0.9 & 0.9 & 0.7 & 1.3 \\
\hline Bladder & 11.1 & 4.0 & 10.0 & 2.9 \\
\hline Conjunctiva & 1.8 & 4.7 & 3.2 & 6.3 \\
\hline Malignant lymphomas (all types) & 6.9 & 9.1 & 2.8 & 6.7 \\
\hline Kaposi's sarcoma & 2.9 & 25.0 & - & 12.0 \\
\hline
\end{tabular}

*Age-standardised rate per 100000 considering African Standard Population.

†Age-standardised rate per 100000 considering World Standard Population proposed by Segi (1960).

rates (ASR) per 100000 of 109.7 for males and 14.1 for females. Cancer of the liver affected mostly the young men population between ages 15 and 44. Age-specific incidence rate reached 264.0 per 100000 in males between 40 and 44 years and 81.5 in women of the same age. Aflatoxin contamination of foodstuffs and chronic carriage of hepatitis B virus (HBV) were considered as major factors to develop cancer of the liver. ${ }^{18}$ In the last decades, incidence of liver cancer in Maputo has shown a marked continuous decrease, being the ASR, for the period 2003-2008, 28.8 and 8.3 per 100000 in men and women, respectively. In a study conducted in 1985 in Mozambique and in the former Republic of Transkei, the aflatoxin levels observed in food samples were the highest ever recorded in any part of the world. ${ }^{18}$

Aflatoxin levels continue to be high in Mozambique. ${ }^{19}$ Its exposure may have decreased through (1) campaigns about the dangers of mouldy food, which is likely to have resulted in increased selectivity during the preparation of foodstuffs, (2) the reduction of peanuts consumption due to economic pressure ${ }^{18}$ and (3) nutrition transition, incrementing animal source food consumption, which probably has replaced groundnuts as the traditional main protein source. ${ }^{20}{ }^{21}$ Although aflatoxin alone does increase the risk of liver cancer, the risk is much greater in carriers of $\mathrm{HBV} .^{22} \mathrm{HBV}$ vaccination was introduced in Mozambique in 2001 and according to WHO, estimations of National coverage rates range from $74 \%$ to $76 \%$. It may be too early to evaluate the effectiveness of this intervention, but a further decrease in the incidence of liver cancer should be expected in the upcoming years.

Cancer of the urinary bladder was the second most frequent cancer in males and third in females in the 1956-1961 period, with most of the cancers being squamous cell carcinomas, a histological variety closely associated with urinary schistosomiasis infection. ${ }^{23}$ Interestingly, this cancer has shown a marked decrease, which could be related to the reduction in the prevalence of schistosomiasis, which has been recently described in southern Mozambique. ${ }^{24}$

Unquestionably, the HIV epidemic has had a significant impact on Maputo's cancer profile. AIDS-defining neoplasm such as cervical cancer and Kaposi's sarcoma (KS) have constantly increased since $1990 .^{7}$ Cancer of the uterine cervix was the second most frequent cancer in women in the 1950s and has become the most frequent neoplasm in the 2000s with an ASR per 100000 of 62.2, one of the highest cervical cancer rates worldwide. ${ }^{1}$ The social disruption caused by the civil war in the 1970 s and 1980s may have favoured the spread of human 
papillomavirus (HPV) infection and other sexually transmitted infections (STI). Although unusual, KS had already been detected in the Mozambican population in the 1950s, similar to other countries in Africa. However, in the 1950s, it was of the typical 'endemic' pattern, involving the skin, particularly the legs, and affecting males, with the risk rising progressively with age ${ }^{25}$ The enormous increase in the incidence of this cancer since the earlier periods ${ }^{26}$ together with the narrowing of the sex ratio has previously been reported in Uganda. ${ }^{27}$

Improvements in the control of HIV and in other STI, such as increased HIV testing and antiretroviral therapy coverage or HPV vaccination (to be implemented nationally in the coming years), and increased coverage of population screening should stagnate and decrease current numbers of HIV-related and STI-related cancers.

Prostate cancer is the most commonly diagnosed cancer among men in Southern Africa and Western Africa. In Maputo, prostate cancer was rarely diagnosed in the $1950 \mathrm{~s}$, whereas in the 2000s, the incidence reaches 61.7 cases per 100000 , four times the rate reported for sub-Saharan Africa. Being a cancer that almost always appears late in life, life expectancy can doubtless explain part of the big rate increase. Screening programmes are unlikely to have played a role, but it is possible that increased awareness and use of diagnostic and therapeutic procedures in patients with persistent urinary symptoms have contributed to the increase observed in its occurrence. Due to the observed racial disparities in prostate cancer risk with higher rates reported among African descendants, genetic susceptibility has been suggested to play a role..$^{28}$

Breast cancer was rarely diagnosed in Mozambique in the 1950s, while its incidence has increased almost 10 times in the 2000s. In many sub-Saharan African countries, breast cancer has now become the most commonly diagnosed cancer. Beyond enhanced detection, reasons for this are unknown, but increases in the prevalence of risk factors for breast cancer such as early menarche, late childbearing, low parity, obesity, which are associated with urbanisation and economic development have certainly played an important role. ${ }^{1}$ Nonetheless, the ASR of breast cancer in Maputo remains relatively low compared with global figures. ${ }^{29} 30$

Finally, the increase in the incidence of cancer of the oesophagus observed in both sexes between the 1950s and 2000s is difficult to explain. A similar increase has been observed in Uganda. ${ }^{27}$ Alcohol, tobacco and cereal-based diets, particularly those relying on maize via nutritional deficiencies associated with such diets or contamination of maize with mycotoxins may have a role in this phenomenon. ${ }^{27}$

\section{Challenges and limitations of cancer surveillance}

High-quality cancer surveillance is crucial to fight the cancer epidemic in LMIC. Vital statistics, risk factor surveys and population-based cancer registries are fundamental for cancer surveillance. ${ }^{31}$ The vital statistics system of Mozambique has been virtually unchanged for more than 50 years. Although there is a comprehensive system for registering births, deaths and other vital events, its coverage and quality are discouragingly low to merit any attempt to use these data for statistics. ${ }^{32}$ Digitalisation, more accurate information and coverage enhancement are needed. Coverage might be improved by immediate registration of all births and deaths taking place in hospitals, preliminarily registration of newborn babies who have not been given a name and allowing unmarried mothers to register their child, regardless the father is away, refuses or is unknown. The lack of an address system and the lack of registered data on migrations within Mozambique as well as to and from other countries, make demographic estimates even more difficult. ${ }^{32}$

Mozambique does not have a national population-based cancer registry. The first Mozambican population-based cancer registry started in Maputo in the 1960s, but disappeared after the independence. After the end of civil war in 1991, the Department of Pathology at the Maputo Central Hospital (MCH, named during the colonial period Miguel Bombarda Hospital) restarted the registration of all cancers with anatomopathological diagnosis. The MCH performed all the pathological testing in the country until 2001, when a Department of Pathology was established at the Hospital Central de Beira, covering the central region of the country. In 2003, the Hospital Central de Nampula, in charge of the north region, also opened a Pathology Department. Today, the city of Beira has a population-based cancer registry and the Department of Pathology at the MCH continues with its registry.

According to the key elements of population-based registries for cancer incidence surveillance proposed by Piñeros et $a l,{ }^{31}$ Mozambique faces several challenges to implement a national population-based registry. First, although after the end of civil war, censuses have been performed in 1980, 1997 and 2007 and intercensual estimates are available, their precision can be questioned because of the long-time periods between rounds or the fluctuating migration patterns. In fact, demographic surveillance platforms were developed in some settings in order to have more accurate population figure. ${ }^{33}$

As a second key element, existence and development of oncological services, access to medical and diagnostic services and quality of medical information should be improved. According to the Mozambique Poverty Reduction Strategic Programme II, ${ }^{34}$ only $36 \%$ of people have access to a health facility within $30 \mathrm{~min}$ of their homes. About $30 \%$ of the population is not able to access health services and only $50 \%$ have access to an acceptable level of healthcare. There is a need for more investment in health system structures and functions. Many health facilities are in urgent need of renovation and maintenance, with lack of basic commodities such as running water, electricity, transport or communication. ${ }^{35}$ But the biggest barrier is the lack of trained human resources capacity. Mozambique has one of the lowest health worker densities in Africa, with three doctors and 21 nurses per 
100000 inhabitants. ${ }^{36}$ There are only seven oncologists in the country and no oncological surgeons. Even so, the country is doing significant efforts to improve cancer diagnosis and treatment through capacity building activities, including increased number of trained specialists, improved infrastructures and equipment. ${ }^{37}$ As an example, immunohistochemistry was introduced in 1993 and fine needle aspiration biopsy assessment in 1996.

Finally, access to information sources and consolidation of data from multiple sources are needed to achieve an efficient population-based cancer registry. The Health Information System in Mozambique is still facing numerous challenges in terms of quality and use of data, mainly due to insufficient and poorly trained health workers, scarce financial resources, inadequate tools for data management and inadequate supervision and feedback. ${ }^{35}$ The recent evolution of surveillance of non-communicable diseases (NCDs), including cancer, has emphasised risk factor surveillance rather than disease occurrence, ${ }^{36}$ which could be improved by strengthening health information systems and health surveys. Mozambique joined the Demographic Health Surveys Program on 1997 and finished the third round on 2011. These surveys provide very valuable data but are mainly focused on communicable diseases and maternal and child health. Incorporation of NCDs and its risk factors would be of paramount importance.

\section{CONCLUSION}

An increase in cancer burden (both in notifications and real incidence) and changes in the cancer profile should be expected in LMIC in the upcoming years, due to the constant growth of population, the higher life expectancy and the increased prevalence of economic transition-associated risk factors.

The case study of Mozambique shows how the country faces the dual challenge of a still high morbidity and mortality due to infectious diseases in the rural areas and the increased incidence of cancers associated with westernisation of lifestyles in urban areas, as well as a rise of cancers related with the HIV epidemic. In addition, the Mozambican healthcare and health-information systems are not prepared to face this epidemiological transition, which deserves increasing policy attention. Similar situations can be expected in other LMIC undergoing a rapid societal and economic transition.

Involvement of all stakeholders, such as the Government, the Health Department, the international organisations, the non-profit organisations working in LMIC, as well as the general population is needed to promote a holistic and equitable approach of this public health priority. Population awareness, the development of an accurate and comprehensive cancer surveillance system, including the establishment of a national cancer registry coupled with precise demographic information, the implementation of effective primary prevention strategies and early detection programmes, improved diagnostic techniques and high-quality medical services are essential to monitor and control the cancer epidemic. It is of particular importance to pay special attention to rural areas and other vulnerable populations. Development of networks and coordination with organisations providing support and sharing knowledge such as the Global Initiative for Cancer Registry Development should be prioritised.

\section{Author affiliations}

${ }^{1}$ Department of Pathology, Maputo Central Hospital, Maputo, Mozambique ${ }^{2}$ Department of Pathology, Faculty of Medicine, Eduardo Mondlane University, Maputo, Mozambique

${ }^{3}$ ISGlobal, Hospital Clínic-Universitat de Barcelona, Barcelona, Spain

${ }^{4}$ Department of Preventive Medicine and Epidemiology, Hospital Clinic-Universitat de Barcelona, Barcelona, Spain

${ }^{5}$ Department of Pathology, Hospital Clinic, Universitat de Barcelona, Barcelona, Spain

${ }^{6}$ Community Health Department, Faculty of Medicine, Eduardo Mondlane University, Maputo, Mozambique

${ }^{7}$ Centro de Investigação em Saúde de Manhiça (CISM), Maputo, Mozambique ${ }^{8}$ Amsterdam Institute for Global Health and Development (AIGHD), Amsterdam, The Netherlands

Contributors $\mathrm{CL}, \mathrm{L} 0$ and AV wrote the first draft. All other authors provided critical comments and drafted the original version.

Funding The authors have not declared a specific grant for this research from any funding agency in the public, commercial or not-for-profit sectors.

Competing interests None declared.

Patient consent Not required.

Provenance and peer review Not commissioned; externally peer reviewed.

Data sharing statement No additional data are available.

Open Access This is an Open Access article distributed in accordance with the Creative Commons Attribution Non Commercial (CC BY-NC 4.0) license, which permits others to distribute, remix, adapt, build upon this work non-commercially, and license their derivative works on different terms, provided the original work is properly cited and the use is non-commercial. See: http://creativecommons.org/ licenses/by-nc/4.0/

(C) Article author(s) (or their employer(s) unless otherwise stated in the text of the article) 2018. All rights reserved. No commercial use is permitted unless otherwise expressly granted.

\section{REFERENCES}

1. Jemal A, Bray F, Forman D, et al. Cancer burden in Africa and opportunities for prevention. Cancer 2012;118:4372-84.

2. International Agency for Research on Cancer (IARC). Cancer incidence and mortality worldwide. GLOBOCAN 2012 v1.0: IARC CancerBase.

3. International Agency for Research on Cancer. World cancer report 2008. Cancer Control 2008;199:512.

4. Stewart BW, Wild CP. World cancer report 2014. 2014;630 http:// www.iarc.fr/

5. Global Initiative for Cancer Registry Development (GICR). International Agency for Research on Cancer. World Health Organization [Internet]. (cited Jan 3 2018).

6. Prates MD, Torres FO. A cancer survey in Lourenço Marques, Portuguese East Africa. J Natl Cancer Inst 1965;35:729-57.

7. Lorenzoni C, Vilajeliu A, Carrilho C, et al. Trends in cancer incidence in Maputo, Mozambique, 1991-2008. PLoS One 2015;10:e0130469-12.

8. Dudwick N, Hull K, Katayama R, et al. From farm to firm. Ruralurban transition in developing countries. Washington DC: The International Bank for Reconstruction and Development/The World Bank, 2011:79-106.

9. Pfeiffer J, Chapman R. An anthropology of aid in Africa. Lancet 2015;385:2144-5. 
10. FAO. Nutrition Country Profile. Republic of Mozambique 2011 [Internet, 2006. Available from:. ftp://ftp.fao.org/ag/agn/nutrition/ncp/ kwt.pdf

11. Forum for Food Security in Southern Africa. Mozambique food security issues paper security. 2003.

12. García-Basteiro AL, Miranda Ribeiro R, Brew J, et al. Tuberculosis on the rise in southern Mozambique (1997-2012). Eur Respir $J$ 2017; 49:1601683.

13. González R, Munguambe K, Aponte J, et al. High HIV prevalence in a southern semi-rural area of Mozambique: a community-based survey. HIV Med 2012;13:581-8.

14. United Nations Development Programme (UNDP). Human development report 2015 work for human development, 2015.

15. Mario M, Nandja D. Alfabetización en Mozambique: Desafíos de la Educación Para Todos. Educ Adultos y Desarro 2006;67.

16. The World Bank. Life expectancy at birth in Mozambique [Internet]. https://data. worldbank.org/indicator/SP.DYN.LE00.IN?locations=MZ (cited Jan 3 2018).

17. Beste J, Pfeiffer J. Mozambique's debt and the International monetary fund's influence on poverty, education, and health. Int $J$ Heal Serv 2016;46:366-81.

18. Van Rensburg SJ, Cook-Mozaffari P, Van Schalkwyk DJ, et al. Hepatocellular carcinoma and dietary aflatoxin in Mozambique and Transkei. Br J Cancer 1985;51:713-26.

19. Warth B, Parich A, Atehnkeng J, et al. Quantitation of mycotoxins in food and feed from Burkina Faso and Mozambique using a modern LC-MS/MS multitoxin method. J Agric Food Chem 2012;60:9352-63.

20. Nnyepi MS, Gwisai N, Lekgoa M, et al. Evidence of nutrition transition in Southern Africa. Proc Nutr Soc 2015;74:478-86.

21. Van Rensburg SJ, Kirsipuu A, Coutinho LP, et al. Circumstances associated with the contamination of food by aflatoxin in a high primary liver cancer area. S Afr Med J 1975;49:877-83.

22. Sitas F, Parkin DM, Chirenje M, et al. Part II: cancer in indigenous Africans - causes and control. Lancet Oncol 2008;9:786-95.

23. Johansson SL, Cohen SM. Epidemiology and etiology of bladder cancer. Semin Surg Oncol 1997;13:291-8.

24. Augusto G, Nalá R, Casmo V, et al. Geographic distribution and prevalence of schistosomiasis and soil-transmitted helminths among schoolchildren in Mozambique. Am J Trop Med Hyg 2009;81:799-803.
25. Taylor JF, Templeton AC, Vogel CL, et al. Kaposi's sarcoma in Uganda: a clinico-pathological study. Int J Cancer 1971;8:122-35.

26. Carrilho C, Ferro J, Lorenzoni C, et al. A contribution for a more accurate estimation of the incidence of Kaposi sarcoma in Mozambique. Int J Cancer 2013;132:988-9.

27. Wabinga HR, Parkin DM, Wabwire-Mangen F, et al. Trends in cancer incidence in Kyadondo County, Uganda, 1960-1997. Br J Cancer 2000;82:1585-92.

28. Bock CH, Schwartz AG, Ruterbusch JJ, et al. Results from a prostate cancer admixture mapping study in African-American men. Hum Genet 2009;126:637-42.

29. GLOBOCAN. International Agency for Research on Cancer (IARC). World Health Organization [Internet]. http://globocan.iarc.fr/Default. aspx (cited 2018 Jan 3).

30. Bray F, Jemal A, Grey N, et al. Global cancer transitions according to the Human Development Index (2008-2030): a population-based study. Lancet Oncol 2012;13:790-801.

31. Piñeros M, Znaor A, Mery L, et al. A global cancer surveillance framework within noncommunicable disease surveillance: making the case for population-based cancer registries. 2017;39:161-9.

32. Brunborg H. Vital statistics. Report from a mission to the National Statistical Institute of Mozambique, 2011.

33. Sacoor C, Nhacolo A, Nhalungo D, et al. Profile: Manhiça health research centre (Manhiça HDSS). Int J Epidemiol 2013:42:1309-18

34. World Health Organization. Mozambique's health system.

35. WHO Country cooperation strategy 2009-2013. Mozambique. 2009.

36. World Health Organization. World health report: working toghether for health, 2006

37. Increasing clinical and research capacity for cancer in Mozambique. A multi-center collaboration between the U.S, Brazil and Mozambique [Internet]. http://thegomap.org/projects/increasingclinical-and-research-capacity-for-cancer-in-mozambique-a-multicenter-collaboration-between-the-u-s-brazil-and-mozambique (cited Jan 3 2018)

38. Sankoh O, Sharrow D, Herbst K, et al. The INDEPTH standard population for low- and middle-income countries, 2013. Glob Health Action 2014;7:23286-6. 